\title{
Tourism in Neuroscience Framework/Cultural Neuroscience, Mirror Neurons, Neuroethics
}

\author{
Ana Njegovanović \\ Correspondence: Ana Njegovanović, Croatia, Zagreb, Kamaufova 3, Croatia. \\ Received: November 11, 2019 \\ Accepted: December 16, 2019 Online Published: December 23, 2019 \\ doi:10.11114/ijlpa.v3i1.4665 \\ URL: https://doi.org/10.11114/ijlpa.v3i1.4665
}

\begin{abstract}
Tourism is a dynamic and competitive industry that requires the ability to constantly adapt to the changing needs and wishes of customers in the uncertain financial global environment posing the problem of attracting tourists. The aim of the paper is to research the involvement of neuroscience through cultural neuroscience, mirror neurons, neuroethics as a new approach to different aspects of tourism. We present the most important research in the field of tourism through existing literature, discuss the limitations of this approach and propose guidelines for future research. In a theoretical approach, given the specific tourist experiences, mirror neurons can contribute to explaining some important aspects of tourism. Investigations lead to a neurological context, where many modes are associated, the language utilizes a multimodal sensory motor system that includes the brain area (concept of empathy, characterization of the traditional anthropological relationship between the host and host of the Istrian region).
\end{abstract}

Research on cultural neuroscience examines how cultural and genetic diversity shape the human mind, brain, and behavior in multiple time scales: state, ontogenesis, and phylogeny.

We particularly emphasize the importance of medical tourism by including empirical research from different disciplines and ethical issues involving individual and population perspectives.

Keywords: epistemology, cultural neuroscience, mirror neurons, neuroethics, medical tourism

\section{Extended Introduction}

Tourism is a dynamic and competitive industry that requires the ability to constantly adapt to the changing needs and wants of customers in an uncertain financial global environment that is a problem for attracting tourists.

This paper outlines an interdisciplinary network of understanding tourism through key principles from mirror neurons that can contribute to explaining some important aspects of tourism in a neurological context, where many modalities are interconnected; -Home- example of the Istrian region) to the culture of neuroscience and neuroethics.

How relevant is neuroscience to tourism in the digital age? Relations between neural architecture and intelligence? The ability to have flexible, intelligent behavior is made possible by the brain's ability to transform itself - by continually updating prior knowledge based on new information and actively generating internal predictions that guide adaptive behavior and decision making. Modern research "points" to the brain as a dynamic and active inference generator that predicts sensory inputs, creating hypotheses about this world that can be tested for sensory signals that reach the brain. Plasticity is key to the emergence of human intelligence - it provides a powerful mechanism for updating past beliefs, generates dynamic predictions about the world, and adapts in response to ongoing changes in the environment. Flexibility is ensured by brain plasticity. Network flexibility (network neuroscience theory) is shaped by structural and functional organization of the brain, which can facilitate or limit the transition of the network from one condition to another. Thus, the transition to an easily accessible condition requires a short, direct path, while the transition to an easily accessible condition requires a long, winding path. Network neuroscience theory proposes that crystallized intelligence incorporates highly accessible representations of prior knowledge and experience and relies on readily available states of the network. Fluid intelligence, by contrast, reflects the ability to solve new problems and exhibit adaptive, flexible behavior. Fluid intelligence involves networks that can move into hard-to-reach, highly flexible condition.

Neuroscience is an interdisciplinary science that works closely with other disciplines, such as mathematics, linguistics, engineering, computer science, chemistry, philosophy, psychology and medicine. Neuroscientists study the cellular, 
functional, behavioral, evolutionary, computational, molecular, cellular, and medical aspects of the nervous system. There are different areas that focus on different aspects, but they often overlap.

Some major branches of neuroscience can be broadly categorized into the following disciplines: Affective neuroscience: how neurons behave in relation to emotions, behavioral neuroscience: how the brain affects behavior., Clinical neuroscience, neurologists and psychiatrists, view nervous system disorders from basic neuroscience findings to find ways to treat and prevent them. Seeking ways to rehabilitate those who have undergone neurological impairment, clinical neuroscientists consider mental illnesses a brain disorder, cognitive neuroscience: how the brain shapes and controls thoughts, and neural factors that underlie.

these processes. During the research, scientists measure brain activity while humans perform tasks. This field combines neuroscience with the cognitive sciences of psychology and psychiatry, computational neuroscience: scientists try to understand how the brain calculates. They use computers to simulate and model brain functions, and apply techniques in mathematics, physics, and other computational fields to study brain function, neuroscience cultures: this field considers the interaction between cultural factors and genomic, neurological, and psychological processes. It is a new discipline that can explain variations in health measures between different populations. The findings can also help scientists avoid cultural bias when designing experiments, developmental neuroscience: how the brain and nervous system grow and change, from conception to adulthood. Information gathering helps scientists better understand how neurological systems develop and develop, molecular and cellular neuroscience: observing the roles of individual molecules, genes, and proteins in nerve and nervous system functioning at the molecular and cellular levels, neuroengineering: using engineering techniques to better understand. replace, repair, or improve neural system neuroimaging: This is a branch of medical imaging that concentrates on the brain, used to diagnose disease and evaluate brain health. It can also be useful in the study of the brain, how it works and how different activities affect the brain, neuroinformatics: this area involves collaboration between computer scientists and neuroscientists. Experts are developing effective ways to collect, analyze, share and publish data, neurolinguistics: how the brain enables us to acquire, store, understand and express language. Helps speech therapists develop strategies to help children with speech difficulties or people who wish to recover their speech after, for example, stroke, and neurophysiology: how the brain and its functions relate to different parts of the body and the role of the nervous system, from the subcellular level to whole organs. It helps scientists understand how human thought works and provides insight into disorders related to the nervous systems.

The role and impact of neuroscience in tourism could be linked to the decisions of individuals based on the integration of different disciplines including medicine, psychology, sociology and tourism. Research into the neural mechanisms of tourists' behavior is the backbone in tourism research. Neuroscience tools measure some components in the human body such as happiness / emotion, satisfaction and reasons for returning to a destination by collecting neurophysiology data, information on cognitive and emotional processes using neuroscientific tools (monitoring and programming) incorporating neurophysiological data into the management information system (We and Hu et al., 2014).

Can we refer to Broomhall (2010), who emphasized that travel is one of the important frameworks for life long learning and Kuha (1995) as a powerful contributor to generic skills, or Werry (2008, p. 18) creates a cosmopolitan authority in the approach of the new learning? In relation to concepts of learning and education based on academic discourse dealing with motivation.

Neuroscience culture is an interdisciplinary field that develops theories and methods in culture and social psychology, anthropology, and social and cognitive neuroscience to explore the interactions of different cultures, psychological processes, brains and genes at different time scales (Chiao, Cheon, Pornpattananangkul, Mrazek, \& Blizinsky, 2013; Han et al., 2013; Kim \& Sasaki, 2014). Culture Neuroscience does not intend to classify people into categories, it shows how our brains are shaped and respond to our sociocultural environment (Han et al., 2013). The culture of neuroscience does not necessarily have to be a look at neural similarities and differences between races and nationalities but to cultures (Chiao \& Ambady, 2007; Chiao et al., 2010). Some studies have pointed to differences in neural activity between people of the same race and the same nationality, but therefore come from different sociocultural backgrounds, different regions (Han et al., 2008; Han et al., 2010), socioeconomic backgrounds (Varnum, Blais, Hampton, \& Brewer, 2015) or cultural values (Ray et al., 2010). The importance of neuroscience culture is to bridge the gap between culture and biology (Causadias, Telzer, \& Gonzales,). Integrating the study of culture with neurobiological processes enhances our understanding of the relationship between the brain and behavior. Neuroscience allows us to understand cultural influences on the brain, most of the culture resting beyond conscious awareness, so the use of brain recognition techniques enables researchers to engage in processes that are not readily available at their conscious level through self-assessments. People may be of the same nationality (for example, one is native and the other is naturalized), but they do not necessarily share ideas, values, practices and beliefs. Chinese and Chinese Americans belong to the same race but may not share the same ideas, values, beliefs of practice (Han et al., 2013). In short, the culture of neuroscience 
considers the interactions between cultural factors and genomic, neurological, and psychological processes. This discipline may explain variations in health measures between different populations. Scientific evidence can help scientists avoid cultural bias when designing future experiments.

Mirror neurons are associated with "mirroring" the behavior of others. Nested in our brains, mirror neurons fire not only while performing an action but also when watching someone else perform the same or similar action. Neuroscientific evidence suggests that mirror neurons play a role in how a person integrates information about himself and others. The relationship between mirror neurons and imitations is related to an evolutionary process that has led us to develop empathy and sharing of one person's feelings by another - connecting people to one another, therefore, an important attribute, and mirror neurons are ideal cells that support cooperative behavior between people. So experiencing and observing empathetic behavior during a journey we have not encountered before can activate our system of mirror neurons. It may be the case that travelers integrate this empathetic behavior as part of their brain - leading to a more cautious interaction with others even after returning home. Changing landscapes can be beneficial to our minds, bodies and even our manners.

Ethical issues arising from neuroscience provides us with the opportunity to refine the tools we use. Particular emphasis is placed on 1) Medical tourism research that has the potential to be cross or interdisciplinary but must bridge the gap between ethics-trained researchers and scholars who do not know the normative framework; 2) Medical tourism research must be integrated into empirical research from different disciplines; 3) Ethical analyzes of medical tourism must include both individual and population perspectives.

The role of medical and health tourism in Istria? To get the outline of potential growth and development, one has to start by defining medical and health tourism. Medical tourism could be defined as a decision to travel with the intention of receiving some form of treatment from dental care, cosmetic surgery, elective surgery, and fertility treatment. Medical tourism is associated with the broader notion of health tourism. For example, Carrera and Bridges (2006, p.447) defines medical tourism as organized travel outside the local environment to maintain and improve health. Thus, medical tourism differs from health tourism in terms of types of interventions, setting up and inputs.

Medical tourism includes travel to receive medical, dental, or surgical care (Medical Tourism Association), and is a fast growing niche market in healthcare, tourism, and hospitality. Medical travelers are motivated to seek care outside their area of residence, including an advanced technology approach, higher quality care, or lower cost of care at the destination (Ehrbeck, Guevara, \& Mango, 2008). This emerging industry is a significant market opportunity for entrepreneurs and investors in the healthcare, tourism and hospitality markets. Catering and tourism companies as well as local governments and destination retailers are positioning themselves to gain a share of the EU medical tourism market worldwide. The terms "medical tourism" and "medical travel" include both hospital and outpatient care regardless of the payer. Medical tourists travel for care, medical tourism includes "tourism aspects" or consumption of "travel related services such as transportation, accommodation and hospitality" (Stackpole \& Associates, 2010). One major implication of recent research is underscoring the global aspect of the market and expanding the reach of the medical tourism market. Medical tourism is a global phenomenon and attracts a wide range of consumers and the opportunity to expand its business by utilizing existing real estate locations and existing clientele without major capital investment. Existing customers who already use the hotel chain for corporate or leisure use may be focused on marketing for medical travel.

The growing trend among Americans indicates the need for affordable treatment options abroad because of their health needs. According to Patients Beyond Borders, medical travelers from the United States seek treatment for a variety of reasons, including cosmetic surgery, dentistry, and orthopedics, mostly traveling to countries in South America, the Middle East, or Asia. Medical tourism is a lucrative business and is developing rapidly in many tourism countries in the world (Favis-Villafuerte, 2009). The medical tourism industry is moving globally at $\$ 60$ billion and its value is growing steadily. Reports from the 2012 Deloitte Center for Health Services state that more than 1.6 million Americans have traveled in the use of some form of medical tourism (Shah, 2013).

Examples of health tourism in the Chinese health services market (significant increase in Chinese tourists' visits). According to a report by Deloitte, China's annual health care spending is projected to grow at an average of 11.8 percent annually from 2014 to 2018, reaching $\$ 892$ billion by 2018. China faces new challenges as more and more people in the country begin to suffer from so-called "life-threatening" diseases such as cancer, heart disease, diabetes and other chronic diseases. According to the latest report The World Health Organization (WHO) on cancer, China recorded 3.07 million newly diagnosed cancer cases, 21.8 percent of the total. there is a widespread lack of confidence in physicians and the health system in general. A 2013 survey conducted by China Youth Daily reported 67 percent of the public did not believe in the professional diagnosis and treatment of doctors. Due to health problems, lack of confidence in medical professionals and populations of 1.3 billion people - many of whom are wealthy and in need of critical care - it should come as no 
surprise that China's medical tourism market abroad is growing at a rapid pace. According to statistics from the Shanghai Medical Tourism and Promotion Platform, every year, about 60,000 Chinese travel abroad in search of medical services, ranging from anti-aging therapy, cancer screening and treatment, birth and treatment of chronic diseases. The Chinese travel in a wide range of medical procedures and treatments; however, those traveling to the United States and Europe usually do so because of critical care that is not available at home or because they consider the level of expertise in China to be less. According to several assisting agencies, patients travel for cancer and cancer treatment, cardiovascular procedures, stem cell treatments, and comprehensive health screenings. Cosmetic surgery is also popular, but most Chinese patients prefer destinations such as South Korea and Singapore, which are closer to home and cheaper than the US and Europe. The main destinations for Chinese medical tourists are the United States, Japan and Germany (Oscar Zhou, CEO of Ryavo Healthcare (http://www.ryavo.com/, headquartered in Shanghai).

\section{Theoretical Background}

Tourism is the world's largest industry and largest factor of peace, driving people around the world and having a strong significance in multiple areas of human life - economic, environmental, material, social and cultural. It is an ideal lens through which to explore the key themes of contemporary social anthropology (locality, identity and alterity, political economy, development, heritage, representation, imagination, commodification) and the global circulation of people (objects, ideas, images and capital) Tourism is an amphitheater of anthropological research, from the emergence of "anthropology of tourism" as a subfield in the 1970s to key theoretical debates in the present. The first term focuses on tourism in relation to globalization, especially with regard to international development; global transformation of people, places and experiences in parts of the "tourism package" package; commodification and representation; heritage building; tourism as a place where the social identities of tourists and tourists can be mobilized, projected and expressed; and the deep penetration of contemporary tourism with such seemingly unrelated spaces of action as medicine, religion, politics. Anthropologists are increasingly interested in the embodiment - that is, the ways in which socio-cultural factors influence the shape, behavior, and subjective experience of human bodies. At the same time, social cognitive neuroscience began to uncover the mechanisms of embodiment by exploring the neural underpinnings and consequences of social experience. If we look at the intersection of neuroscience and anthropology, we can expand our understanding of the relationship between the human brain and their socio-cultural context. These are: the social construction of emotions, cultural psychiatry, and the embodiment of ritual.

An Interdisciplinary Network of Tourism Understanding of Key Principles from Mirror Neurons that Can Contribute to Explaining Some Important Aspects of Tourism to a Neurological Context, Where Many Modalities are Related, Language exploits a multimodal sensory motor system involving the brain area (concept of empathy, characterization of a traditional anthropological guest-host relationship) to cultures of neuroscience and neuroethics as a possible avenue for involvement in the strategies of modern digital age tourism.

The understanding of mirror neurons arose from discoveries localized in motor pathways. Motor mirror neurons provide real-time imaging of the physical actions of others, which in turn are automatically internalized within the observer (Iacoboni, 2014). The mirror study of Rizzolatti neurons presented earlier was defined by the type of mapping. The presence of mirror neurons in the macaque monkey, the area of the F5 ventral portion of the premotor cortex, was first investigated (di Pellegrino, Fadiga, Fogassi, Gallese \& Rizzolatti, 1992; Gallese, Fadiga, Fogassi, \& Rizzolatti, 1996). Christian Keysers and Valeria Gazzola (2009) have suggested that these mirror systems in various parts of the brain can be thought of as systems that generally promote social cognition by triggering self-sensory and emotional representations of others. If we can consider the functions of mirror neurons in terms that an individual experiences directly through another, then it logically follows that the activation of neurons would be indistinguishable from other brain function; it is not isolated or localized, but rather broadly interconnected by dispersed pathways and modalities (Fadiga, Fogassi and Rizzolatti, 1996). The modalities of mirror neurons are expansive. Auditory limitations of mirror neurons indicated that the sounds of the action alone were sufficient to obtain a mirror neuronal response (Kohler et al. 2002). Mirror neurons are involved in speech processing (Rizzolatti \& Craighero, 2004), musical processing and interpretation of emotional components of music (Molnar-Szakacs \& Overy, 2006), somatosensory data indicate that touch involves a visual mirror system that can be (Ebisch et al., 2008) modeled by personality factors such as openness to experience and awareness (Schaefer, Rotte, Heinze and Denke, 2013). Iacoboni expanded his research to a closely related concept of intentions regarding the mirror neural system, and ultimately empathy (Iacoboni et al., 2005). The connection with empathy has been explored by linking the known modality of the mirror neural system, recognizing an intentional action in the motor premotor cortex with emotionally charged actions that might elicit empathic responses such as facial expression recognition. Vicarious activation has been found to occur in monkeys as they look at other person's facial expressions (Ferrari et al., 2012; Ferrari, Gallese, Rizzolatti and Fogassi, 2003). In addition, there may be a right hemisphere of the mirror system that informs emotional empathy (Leslie, Johnson-Frey and Grafton, 2004). Empathy is directly involved in the mirror activation of neurons through the observed facial expressions, partly because 
we associate facial expressions of emotions and partly because emotional experiences can be activated indirectly. Empathy is, in many cases, achieved through feeling like you are another. This emotional understanding is difficult to achieve when there is no sensory or contextual information available. By experiencing through the other, one can better attain physical understanding, which in turn leads to emotional understanding and the embodiment of empathy. Even though most individual trials of neuronal empathy have been performed on monkeys, there is evidence to suggest that mirror neurons and their definition of characteristic participation in empathy translate to the human brain.

Neuroscience has become an influential force in industrial society research. Development and rise are in many ways parallel to genomics, neuroscience has been involved as a valuable source of information in "what makes us human," and as a potential source of much-needed therapeutic interventions for a range of disorders and new technologies to improve cognitive, emotional and social skills. Huge financial and symbolic resources have been invested in small and large projects, including the large US BRAIN initiative and the EU Human Brain Project. The public fascination with "neuro" is illustrated by the abundance of popular brainstorming available, the prevalence of fMRI and PET brain imaging in the media, 2016NBI 2016. Why Neurological Research? We will briefly address brain and anthropology. Many aspects of neuroscience require continued critical engagement from anthropology and related disciplines. In particular, it is necessary to examine the extensive circulation of discourses and resources that characterize the rise of neuroscience and associated neurotechnology. Such activities may explore, for example, distributive justice issues. What is the opportunity cost of major investments in promoting neuroscience projects? Similarly, anthropological work should continue to examine the ethical and political implications of international tissue economies, such as those of emerging brain biobanks. Anthropology and cultural neuroscience indicate an understanding of the complex relationships between body, brain, and environment. Anthropological insights can provide the basis for ethnographically oriented laboratory studies that go beyond neural mapping to explore the neural substrates of complex human behavior and experience. Thus, ethnographic research can contribute to rich data on the embodiment of normal and pathological emotional experience and the embodiment of social knowledge through ritual practice. This data can form the basis for robust hypothesis building, and the development of environmentally valid experimental designs. We have also argued that laboratory studies should be complemented by field research using portable measurement devices to provide data on dynamic, in situ neurophysiological responses to the course of social experience.

In recent years, cultural anthropologists have become increasingly interested in the embodiment or ways in which socio-cultural factors influence the shape, behavior, and subjective experience of human bodies. For example, numerous cultural anthropologists have theorized the profound impact of meaning on physical experience, from the influence of metaphor on experience and disease expression (Kirmayer, 1992; Jenkins and Valiente, 1994; Low, 1994) to the impact of socialization on everything from posture to taste (Bourdieu, 1977, 1990; Strathern, 1996; Kontos, 2006). However, for various reasons, discussions of incarnation in the field of cultural anthropology generally lack an adequate account of the biological or cognitive (i.e., memory, attention) mechanisms through which symbolic and social processes shape bodily functioning and experience (R. Seligman, sent to publication). Increasingly sophisticated tools have been used by biological anthropologists, including methods in endocrinology (Worthman and Stallings, 1997; Flinn and England 1998), psychoneuroimmunology (McDade et al., 2000, 2007) and psychophysiology (Dressler, 2000; Gravlee and Dressler, 2005; Decaro and Worthman, 2008) study the effects of the environment on human physiology. However, physiological measures are often used as a static outcome of social forces rather than as indicators of how physiological systems function dynamically over the course of social experience. Biological anthropologists have not studied cultural embodiment at the level of central nervous system function or closely related parameters (electroencephalography (EEG), brain potential (ERP). Despite the fact that a number of anthropologists advocated and even participated in speculative work along these lines (Lex, 1979; Turner, 1983). Anthropologists have access to cross-cultural knowledge and relativistic epistemology that can help uncover the subtle cultural biases that may exist in current experimental designs. Research in the culture of neuroscience emphasizes the importance of using a comparative approach in the study of neural substrates of cognition. However, we also find some pitfalls. Activation of different neural mechanisms represents completely different and even unrelated responses to the same task. Neurobiological research has shown that the environment - including the socio-cultural environment - significantly contributes to the structure and function of the nervous system by influencing experience before and after maturation (Changeux, 1985; Ochsner and Lieberman, 2001; LeDoux, 2002; Blakemore and Choudhury, 2006; Lieberman, 2007). Such studies have shown that social / cultural construction of the brain involves effects at both high and low levels of cognitive function (Han and Northoff, 2008). For example, a recent attention study found that fewer neural resources were obtained in the service of attention by a culturally prominent task, compared with a task that was not consistent with cultural highlights (Kitayama et al., 2003). In another recent study, Chiao et al. they found that even very automatic responses, such as the activation of the amygdala in response to facial expressions of expression, appear modulated by embodied representations of one's "in-group" (Chiao and Ambady, 2007). On the other hand, studies show that high- and low-level cognitive processes can be shaped by the same socio-cultural influences. For example, self-style or understanding of personality as more 
independent or interdependent can influence perception (recent research) More specifically, the cognitive foundation for self-construal has been associated with perceiving specific visual goals beyond their context and a greater ERP component in response to the task of local perception. While interdependent self-construction is associated with a tendency toward more global visual perception and a larger component of ERP in response to global goals (Lin et al., 2007). Thus, key culturally specific aspects of social orientation can penetrate basic cognitive processes, such as visual perception. Anthropologists can contribute to such research by using ethnographic data obtained through intensive study in field situations, through which they get to know the culture from an insider's perspective. Such data can be used to develop new hypotheses and study designs that push beyond the identification of neural substrates associated with isolated cognitive tasks, and better capture the contingent and socially embodied nature of human cognition. Cultural neuroscience has so far been primarily concerned with the project of documenting cultural differences in functional neural mapping of cognitive and emotional processes. However, Ochsner and Lieberman (2001) have argued that the ultimate goal of socio-culturally informed research in neuroscience should be to move beyond mapping to the exploration of complex human behaviors and experiences. Functional neural map knowledge should be applied in the study of elements of human experience that exemplify the complex interactions of mind, brain, and environment. Exploring neural substrates of culturally unique patterns of experience, behaviors, or forms of knowledge - such as trance and meditation, for example, can help us better understand the cognitive affective processes they use (narrowed attention, perceived distortion, self-deception, memory suppression), as well as cognitive and affective transformations that facilitate (Lutz et al., 2008 - Compassion Meditation Study). Such research can shed light on the nature of the more widespread elements of lived human experience and the cognitive-affective and neural correlates of these phenomena. For example, applying neuroscientific methods to study religiosity or spirituality can help us better understand the powerful embodied effects of religious belief (Bernston et al. 2008; Kapogiannis et al. 2009).

How to define neuroethics and what is the link with tourism / medical tourism?

It is a field that examines the implications of neuroscience on man's understanding, ethics and politics, and the links between the advancement of neuroscience and the world of politics and ethics.

Ethical dilemmas arise when we think of brain imaging techniques that could help us discover when someone is lying or making assumptions about reasonableness or guilt in criminals with different brain characteristics. Questions about the use of brain imaging in the workplace, marketers use neuroscience studies to find ways to influence decision making and shopping. However, given tourism, it may be more appropriate to define a cosmopolitan ethic. "By definition, cosmopolitan ethics provides a system and approach that is universal in the appreciation of different norms and morals that represent and contribute to international discourses and activities. Cosmopolitan neuroethics must establish and deliver a wide variety of ethical ideas, ideals and constructs so that it respects and incorporates the cultural diversity of the contemporary global stage. "(Dr. James Giordano is Professor of Neurology and Biochemistry, 2018)," Cosmopolitan neuroethics is the moral of the whole human species, and it should also provide ethical advice that is essential to all of humanity while respecting cultural differences. There is growing awareness that neuroscience and neurotechnology are increasingly international. It is common for basic and translational research to be carried out by teams of researchers from different countries, with experimental applications quickly crossing national boundaries. Neuroscience is destined to be global; providing real-world neuroethics guidance must also be global in scope and behavior "(Dr. John Shook teaches philosophy at Bowie State University, Maryland, 2018). and what is called ethical dumping - the practice of conducting research in countries where ethical standards are considered younger - resources and mechanisms need to be developed that allow open and sensitive discourse about the different needs, values and norms that contribute to the philosophy and ethics of different cultures. It is also important how they can be involved in undertaking multinational projects or when deciding on the multinational use of information, techniques and tools created in country-specific research programs. "(Dr. James Giordano, 2018).

Emotions are complex phenomena. They modulate and direct behavior as a set of biological, social, and cognitive components. Theoretical assumptions emphasize one or more components. Cognitive theories (Clore \& Ortony, 2008), social constructivist theories, and an integrative approach (Averill, 1980; Bodor, 2004; Harre, 198 and biological theories (Darwin, 1872/1963; Buck, 1985; Nábrády, 2006; Strongman, 2003).

\section{The Complex Role of Mirror Neurons}

Mirror neurons are similar to other brain neural cells. They are like other neurons in that the cells that are interconnected are synapses on their dendrites and axons, interacting through chemical signals and spreading information electrically down to the cells forming a complex network of information transmission.

Research in the mirror neuron literature has been reported 20 years ago (Dipellegrino et al. 1992), investigating the area of the monkey brain that controls hand actions and mouth procedures (Gentilucci et al. 1988; Rizzolatti et al. 1988). All of these actions are crucial for normal daily functioning. 
There is scientific literature available on the study of mirror neurons in humans using non-invasive forms of brain testing. The four techniques used are functional magnetic resonance imaging ((Iacoboni et al. 2005), EEG (Oberman et al. 2007), magneto-encephalography (Hari et al. 1998) and transcranial magnetic stimulation (Fadiga et al. , 1995; Aziz-Zadeh et al., 2002) Although the data obtained by these techniques are not as convincing as the data obtained from single-cell recordings, they are still extremely valuable. in the brain with behavioral variables. The data obtained confirm initial intuitions about the role of mirror neurons in social behavior. Areas of the human brain with mirror properties are associated with imitation (Iacoboni et al., 1999) and empathy (Carr et al., 2003). Some research shows an association between individual differences in empathy and activity in mirror neural areas (Pfeifer et al., 2008). The more empathetic the subject, the greater the activity during imitation (Pfeifer et al., 2008) or while observing actions (Kaplan and Iacoboni, 2006) or emotional expressions of other people's faces (Pfeifer et al., 2008), including pain (Avenanti et al., 2005). Patients who are impaired by social interaction, such as patients with autism spectrum disorders, show diminished activity in mirror neural areas (Dapretto et al., 2006). These direct us that mirror neurons are important for an easy, automatic understanding of other people's mental states (Iacoboni, 2009), and may also be the basis of automatic imitation (Cross and Iacoboni, 2011). It is imperative to pay attention to neuroscience data as they suggest forms of human automatic behavior that require careful consideration when planning interventions and policies that seek to reduce infectious violence. In short, "mirror neurons are brain cells specialized in actions. Obviously cells for social interactions are critical, but they cannot explain unsocial cognition and every brain cell and every neural system does not operate in a vacuum. Everything in the brain is interconnected "(Iacoboni, 2006). Language evolution was considered a key empathic function because vocalization or the way people make sounds is an important function of human social behavior. Although neuroscientists identified Broca's brain region (Keysers, C., Kohler, E., Umilt, M. A., Nanetti, L., Fogassi, L., \& Gallese, V., 2003), they were confused by the area responsible for speech. how it affects other parts of the brain because no clear mechanism has been observed. However, because mirror neurons play a key role in motor control, Gallese hypothesized that their activities correlate with mouth-forming speech and brain-understanding speech (Gallese, V., 2003). Hypothesis "from mirror neurons to empathy,.. Despite a series of controversies related to Gallese research, research on mirror neurons in Gabriella Cerri's experiments at the University of Milan used external electrical impulses to shock parts of the human mirror neural system to see if it would cause the vocal cords to trigger an otherwise unprovoked response. The results indicated that the mirror neural system assumes an additional, yet vital role in speech (Keysers, C., Kohler, E., Umilt, M. A., Nanetti, L., Fogassi, L., \& Gallese, V., 2003; Cerri , G., Cabinio, M., Blasi, V., Borroni, P., Iadanza, A., Fava, E.,.,, Bello, L., 2014). Without spoken language, written language would never become a reality (Keysers, C., Kohler, E., Umilt, M. A., Nanetti, L., Fogassi, L., \& Gallese, V., 2003; Cerri, G., Cabinio. M., Blasi, V., Borroni, P., Iadanza, A., Fava, E.,.,, Bello, L., 2014). This has laid the foundation for the development of empathy in humans (Gallese, V., 2003; Sigmund, K., 2017; Keysers, C., Kohler, E., Umilt, M. A., Nanetti, L., Fogassi, L., \& Gallese, V., 2003). To the scientific community, this discovery meant that language was a response that stemmed from the empathetic nature of humans. As more empirical evidence suggests that mirror neurons play a vital role in empathy and other actions, scientists are more confident in its importance in the human population (Heyes, C., 2010).

Can mirror neurons explain the brain mechanisms of empathy and the role of empathy in tourism? Empathy is a moral and social resource. It helps us to make friends, care for the needy and not be cruel. But what happens to our brains when we empathize? Can neuroscience help us explain why we care? Professor Baron-Cohen points out that there is a neuroscientific consensus that empathy occurs in at least 10 areas of the brain. Areas of the brain are activated not only when we feel a sensation or feel ourselves, but also when we see other people experience it. The first round is the "medial prefrontal cortex" (MPFC) - the "social center" of our brain, the dorsal MPFC is involved in thinking about the thoughts and feelings of others as well as our own (Professor Baron-Cohen) and the ventral MPFC is very active when people think more about themselves but about others. The next round of empathy is the inferior frontal gyrus (IFG). Research has shown that patients with impairments in this area have trouble recognizing emotions in other people's faces. The amygdala is also involved in recognizing facial expressions. The amygdala is involved in recognizing facial expressions. and when we ourselves have a tactile experience. "We still know very little about individual differences in empathy. To solve these puzzles, we will need elegant experimental research. "Prof. Simon Baron-Cohen.

From imaging studies of the human brain, it can be seen that the anterior cingulate cortex (ACC) region is active during pain, and may become active when observing pain in others. The fact is that mirror neurons are already in the motor system of the brain, both theories have been tested. The first was that there are mirror neurons in the ACC that "trigger our own sense of pain and reactivate when we see the pain of others," and the second is that "this is why we need and feel pain while seeing the pain of others." Lack of empathy can occur with psychopathy and other disorders. "It also shows us that empathy, the ability to feel with others' emotions, is deeply rooted in our evolution." (Prof. Christian Keysers). 
Insufficient research on empathy as a key term in tourism policy, planning or strategy gives us poor insights into empathy. Empathy regarding intercultural aspects of tourism - tourist encounters of people from different cultures (Tucker, 2016) - and empathy in hospitality (Barlow \& Maul, 2000). Thus, empathy is important in many tourism situations, but it is also affirmative that empathy towards people, which is the focal point of a destination strategy, is a key skill for any policy-maker, planner or strategist. According to Merriam-Webster (lack of a better academic source) empathy is "the action of understanding, awareness, sensitivity and redundant experience of feelings, thoughts, plans or strategies can be completely useless. Losing time and money. Unfortunately, there are enough examples of this worldwide. or strategy can be completely useless Loss of time and money Unfortunately there are enough examples around the world Although empathy is not an important management tool, the value it provides is quite intrinsic Somewhat recognized by the hospitality industry but few hotels have actually made progress "Measuring empathy within hotel employees" (Shaveli, 2016) is both recognition and testing in empathic behavior (especially in hotels and by hotel staff) It is extremely important for researchers and practitioners not only to determine the importance of empathy in hospitality services, but also to provide potential causation to the inexperienced mode in which empathy has been used a (and therefore leaves grounds for a potential solution to be developed later). It is important to highlight the basics of empathic behavior. "Empathy in Early Childhood: Genetic, Environmental, and Affective Contributions" (Knafo, 2009) Takes a Psychological Approach to Empathy It is important to underline the knowledge of emotions that influenced the severity of empathy.

Empathy and empathetic behavior are integral to the management of the hospitality industry, but related to this, it is imperative in life to master. Being able to relate your work and life experience to someone else's, to better understand his or her perspective can enhance one's relationships, attitudes, and being.

\section{Neuroscience in the Tourism Framework}

Cognitive neuroscience of emotions deals with the role of emotions during cognitive processes ((perception, attention, memory, decision making), its neural basis at the cortical and subcortical level, the perception of emotional stimuli and individual differences in responding to emotionally evocative stimuli.

The amygdala (the corresponding brain structures responsible for emotions) plays a crucial role in emotional life. Almond shape bilaterally located in the medially temporal lobe. Modern brain imaging techniques (fMRI, PET, MEG, EEG) have shown that the amygdala plays a role in emotional conditioning, storing emotional events and encoding emotional cues, especially facial expressions (LeDoux, 1996).

Insula is a multimodal sensory region in the Brodman area. Its activation is revealed during emotional induction when we recall an emotional event (Phan, Wager, Taylor, \& Liberzon, 2002). Coordinates sensorimotor responses to unpredictable threatening content (Szily \& Kéri, 2008) and cognitive tasks (Reiman et al., 1997). The signaling role of insula alarms the body during a threat state. In doing so, we explain self-initiated and withdrawn guilt, shame of sadness, and unpleasant stimuli activate the insula (Lane, Reiman, Ahern, Schwartz, \& Davidson, 1997; Lane, Reiman, \& Bradley, 1997).

The anterior cingulate cortex of Gyrus cingulate belongs to the limbic system. His dorsal subdivision is associated with cognition in the Brodmann area (cingulate area) and his ventral subdivision is associated with affective processes in the Brodmann area.

Understanding the feelings that evoke tourism experiences play a vital role in the tourism industry (Gretzel, Fesenmaier, Formica and O'Leary, 2006). Emotional arousal is a major motivation for buying and consuming products (Bloch, Sherrell, \& Ridgway, 1986; Goossens, 2000). , hedonic consumption (Alistair, 2006), adventure, escape, fun (Otto and Ritchie, 1996), happiness (Gretzel et al., 2006), pleasure (Floyd, 1997). Fantasy, feelings and fun (Holbrook, 2006) and positive and enjoyable emotions (Tung \& Ritchie, 2011).

Measuring emotional responses to visitor experience requires research (Mauss \& Robinson, 2009). Emotional status research on a set of effective objects (Hosany \& Gilbert, 2010; Hosany \& Prayag, 2013; Kyle \& Lee, 2012; Pearce \& Coghlan, 2010; Walters \& Sparks, 2012), an approach collectively called the "self-report" method (Chamberlain \& amp; Broderick, 2007; Jacobs, Fehres, \& Campbell, 2012; Mauss \& Robinson, 2009; Poels \& Dewitte, 2006; N. Ravaja, 2004; Wang and Minor, 2008). Although useful, such self-report methods may include cognitive biases (Paulhus, 2002), seek socially acceptable responses (Wiles \& Cornwell, 1991); there is no gold standard measure of emotional response (Mauss and Robinson 2009, p. 228). Measurements of emotions require the use of multiple methods (P. Lang, 1988; Mandler, 1975; Rachman, 1978) with the combination of different measures. Thus EDA (electro-dermal analysis) is a measurement of autonomic nerve activation. The system (ANS) controls most of our organs and muscles that we are largely unaware of (Dawson, Schell, \& Filion, 2007; Jacobs et al., 2012; Poels \& Dewitte, 2006). Heart rate response (HR) is the measurement of heart rate over a period of time (usually one minute) and is most commonly used in psychophysiology (N. Ravaja, 2004). Facial muscle activity is an important physiological indicator of internal 
psychological activity. Contraction can be measured using the electrodes involved, skin electronics (Mauss \& Robinson, 2009; Tassinary, Cacioppo, \& Vanman, 2007; Wang \& Minor, 2008). Measures of movement or eye tracking are often complementary to other psychophysiological methods. Eye movements have been found to be associated with memory (Krugman, Fox, Fletcher, Fischer, \& Rojas, 1994; Wedel \& Pieters, 2000) and attention (Pieters \& Wedel, 2004). It should be emphasized that measures of eye movement may be affected by excessive blinking or tears (Pieters, Rosbergen, \& Wedel, 1999). Vascular activity measures the recording of participants' blood pressure, volume, and pulse and are associated with fear (Fredrikson \& Öhman, 1979). Vascular activities are easier to monitor because measuring instruments are smaller compared to other techniques (Wang \& Minor, 2008).

Neuroscience motivations in tourism require first insights into social neuroscience. Social neuroscience is an interdisciplinary field dedicated to the study of neural, hormonal, cellular and genetic mechanisms, and the study of the connection and impact between the social and biological levels of an organization. It emerged in the early 1990s as an interdisciplinary academic field dedicated to understanding how biological systems conduct social processes and behaviors, using biological concepts and methods to inform and refine theories of social processes and behavior, and using social and behavioral concepts and data to inform and refine the theories of neural organization and functions (Cacioppo and Berntson, 1992). As Llinás (1989) noted. The brain, however complex, can only be understood from a cellular perspective. This perspective has been a cornerstone of neuroscience over the last 100 years."

Tourism, as a form of human mobility, is a major contributor to the reduction of our planet. Tourism is important for addressing the challenges we face because of its role in delivering an inclusive spread of global knowledge, awareness and awareness. New technologies are launching products, ideas and people across our planet in less time than they could have ever imagined. This process of time and space compression (Harvey, D. 1990) results in increasing economic and cultural globalization (Gay, 2016). Compression of time and space and population growth are pushing for a broader global awareness as the only way that people will be able to understand and navigate the ever-evolving world.

Travel benefits relate to desirable outcomes of going on holiday or vacation (Neuhauser H, Leopold M, von Brevern M, Arnold G, Lempert T. 2001). Examples of travel benefits are health, socialization and inclusion (Ahn YJ, JankeMC. 2011). Involvement, which is a motivational variable towards travel, includes decision making about travel (Smallman C, Moore K, 2011) Decision making is a process that involves many sub-decisions, which continually occur from intent to deciding where to go and beyond. Most of the time, when individuals choose to travel to a particular destination, they are based on contextual facts or descriptions.Others may decide to perceive or evaluate their previous travels.Therefore, the decision-making process is complex and behavioral or self-reporting measures may not be sufficient. Empirical evidence on the benefits of travel, research on tourism decision-making is still lacking, and the link between neuroscience and travel remains relatively under-explored.

Neuroscience Electroencephalography (EEG) and Functional Magnetic Resonance Imaging (fMRI) could complement existing travel behaviors. Dopamine is considered a key substitute for intrinsic motivation (Baik JH, 2013) and has immediate behavioral effects (Rutledge RB, Scandali N, Dayan P, Dolan RJ., 2018). Dopamine neurons in the midbrain transmit signals in response to beneficial and irreversible visible experiences (Bromberg-Martin ES, Matsumoto M, Hikosaka, 2010). As such, dopamine can be used as an indicator of travel experience and behavior. Increased activity within the dopaminergic value system will indicate intrinsic motivation when an individual engages in travel activity (involvement) Furthermore, increased dopamine levels in the striatum and prefrontal cortex are associated with positive affect and control of voluntary action (Rigoni D, Demanet J, Sartori G., 2015). Our actions can be driven by intentions, incentives or intrinsic values. Recent neuroscience research has yielded some results in thinking about growth and intrinsic motivation. With the advancement of neuroscience and motivational studies, there is a global need to use this information to inform educational practice and research.

In the 21 st century, there has been a great increase in research on growth thinking and intrinsic motivation in learning. Constructions of thinking and motivation have been important hotspots among educators who want to make a positive impact on students 'learning and outcomes. The underlying mechanism for students to have their own agency in finding new knowledge is intrinsic motivation. However, much of this research has relied on quantitative approaches to evaluate students' self-reports of motivational regulation and learning outcomes (Akioka E., Gilmore L., 2013) Some of these quantitative findings are used to generalize to school conditions. Although multiple opportunities for motivating and learning students were identified in quantitative analyzes, they did not provide a detailed understanding of students' motivational processes. Neuroscience methods can offer new insights into student motivation and learning processes.

\section{Review of the Scope and Importance of Medical Tourism}

Medical tourism is focused on discovering the ideal strategies, opportunities, challenges and future for providing a superior personalized experience for patients, as well as decoding future medical tourism trends globally by ensuring prosperity for all, by establishing corporations and sharing ideas. 
The global medical tourism market is one of the fastest growing and at the same time the most profitable in the healthcare sector. The emphasis on advanced treatment within minimal cost, better patient experience and lack of home-based expertise are responsible for the growing popularity of medical tourism worldwide. According to Global Health Resources, approximately 11 million patients travel each year for medical care, accounting for about 3.0-4.0\% of the world's population. The availability of better treatment options at a minimal cost, the superior quality offered by destination hospitals and better patient comfort are significant factors driving the growth of the global medical tourism market. Increased demand for customized medical services, state-of-the-art medical surveillance and increasing patient awareness due to promotional activities of medical tourism by governments as well as healthcare institutions increase demand for medical tourism over the forecast period.

What motivates people to seek treatment outside their local region does not offer simple answers. People's health situations are unique, as are their financial situations. Travel experience and a person's view of globalization can motivate them to go abroad for treatment.

According to research conducted on motivational factors, there are key motivators that drive people to choose medical tourism (Crooks et al., 2010). Travel-based motivational factors can help you choose your doctor. Medical trips involving an optional destination on a sunny beach in combination with a doctor can help and motivate the patient to choose between a local provider or a doctor from a foreign provider. Knowledge of local customs, food and languages can play a role as a destination for some, especially for those who may have moved abroad and are traveling back to their homeland for medical purposes. One factor that has both an implicit, if not explicit, role in destination selection is the image of the destination, especially given the quality of medical care and the security of the country for both tourists and medical recovery (Khan 2016). Measuring the destination image is complex because they differ between populations, a meta-analysis of factors that are tangentially related to the destination of the image, such as quality of care, economic status, security and infrastructure to a lesser extent (Dehdashti 2016). The destination image plays a significant role and can also affect the satisfaction of the process after the process is completed.

A brief outline on tourism in Croatia / Istria. Certainly, the application of neuroscience (both in the Croats / Istria region) requires the necessary research to understand how direct and unconscious emotional and cognitive responses as natural processes lie in the preferences of the tourist destination and ultimately the decision making. However, it should be emphasized that tourism research is a field for understanding the brain bases of the complex formation of preferences and choices, as well as the choice of destination for health tourism.

Tourism, with 16 percent, accounts for the largest share of GDP (Croatia). The share may increase if health tourism is developed with competitive prices, modern equipment, top-notch treatment with programs in neurology, traumatology and orthopedic surgery, dentistry, gynecology and assisted reproduction, ophthalmology or "life-threatening" programs in the world market. Many non-tourism activities are also involved in health tourism, which creates many positives.

Can Istria develop the Institute of Neuroscience (INS) as a center of excellence for neurological therapy, rehabilitation, training, research and development $(R \& D)$ and a destination for medical tourism? Neurological disorders are one of the leading health challenges globally affecting one billion people and the first cause of disability in the world (WHO). In other words, one in six has a neurological disorder. $12 \%$ of them may die or have "life-threatening" programs.

The geographical location of Istria near the main land and sea routes of central Europe, the Mediterranean climate, the proximity to the warm sea and natural beauty is the nucleus of tourism development with human resources as an infrastructure for attracting medical tourists from all over the world.

\section{Drawings on the Epistomology of Tourism}

Epistemology in tourism explores the character of tourism knowledge, the sources of tourism knowledge, the validity and reliability of claims made from knowledge of the outside world of tourism, the use of concepts, the boundaries of tourism studies and the categorization of tourism. The production of knowledge points to his need for construction for the digital age. The current state of fragmentation prevents the creation of a common epistemology but also leads to a wider misunderstanding.

Although tourism and hospitality have experienced rapid growth that has led to changes in the modern way of life in the world (Crouch, 1994; Vanhove, 2011; Pigram and Wahab, 2005), its experiential nature makes it vulnerable to global threats and threats (Larsen and Brun, 2011; Korstanje and Olsen, 2011). The rise of (jihadist) terrorism beyond the borders of the Middle East has paved the way for policies to protect tourist destinations. Significant efforts and resources have been made to understand and mitigate the negative effects of terrorism (Tarlow, 2006; Schroeder et al., 2013; Bassil, 2014; Bassols, 2016). We live in a world manipulated by emotions (Bigne and Andreu, 2004; Bleiker and Hutchison, 2008). Accordingly, Tribe (2010) indicates that the epistemology of tourism is facing a serious crisis due to the diffusion of produced knowledge as well as the indifference of the international academy in setting a clear single 
agenda for scholars to follow. Thus, the "indiscipline of tourism" shows some of the claims that revolve around the fragmentation of different studies and approaches among academics, thus preventing the maturation of the discipline as a serious option (Tribe, 1997).

There are anti-centrist terrorist cells targeting tourist destinations - (example the assassination of an Israeli team at the Munich Olympics - September 1972) - (Tarlow, 2014) or the Luxor massacre, -Egypt, 1997- (Sönmez, 1998), it is no less true that the September 11, 2001 attacks on the World Trade Center triggered new tactics by emerging radical groups. Jihadist terrorism "is a mass transport vehicle against innocent tourists and civilians (Diken and Laustsen, 2002; Diken, 2011; Sheller and Urry, 2006; Hall et al., 2012; Korstanje, 2017). Luke Howie warns that terrorists do not want many people to die, but many people watching! Although terrorists need to attract the attention of the world public by articulating violence, fear, and extortion, the mass media profit from terrorism news, creating a vicious circle that is very difficult to break (Howie, 2012). As distinguished professor David Altheide, he argued that terrorists encourage panic discourse not only because the state has unilaterally accepted their claims, but also to forge popular forms of entertainment that benefit governments (Altheide, 2006, 2009, 2017). The authors of "The Political Economy of Terrorism" wonder if terrorists will choose places of tourist consumption for their strikes. Although this book has become one of the most cited studies of terrorism research, it remains unknown to tourism scholars. Enders and Sandler (2011) explored the rational interests of terrorists as an interplay between costs and benefits. According to profit maximization theory, (the core of the classical economy) Enders and Sandler explain that tourists are not familiar with the places visited and the presence of tank security forces, tourist destinations offer lower costs for their attacks. At the same time, the profits that terrorists often receive are greater as news is packaged globally and spread by the media to be eaten by large audiences. The effectiveness of terrorism for spreading terror is based on the fact that laymen think that what happened at the affected destination will be repeated later anytime, anywhere. In this way, the economy of terrorism reveals two important things. On the one hand, the surprise factor associated with chance plays a vital role in creating a fear message that benefits terrorists. On the other hand, easy access to hotels and beaches makes tourism more attractive than other places for terrorist activities. In addition to the benefits of backward transparency, economic theory emphasizes the importance of "precautionary principles" and multivariable analysis to understand why some destinations are more vulnerable than others (easy access to hotels and beaches makes tourism more attractive than other sites for terrorist activities. emphasizes the importance of "precautionary principles" and multivariable analysis to understand why some destinations are more vulnerable than others (easy access to hotels and beaches makes tourism more attractive than other sites for terrorist activities. With the benefits of looking back, economic theory emphasizes the importance of "precautionary principles" and multivariable analysis to understand why some destinations are more vulnerable than others (Ryan, 1993; Pizam and Smith, 2000; Pizam and Fleischer, 2002). Economic theory focuses on the negative effects of terrorism that underpin the new platform which measures the resilience of a destination in the context of risk ( Paraskevas i Arendell, 2007 ; Uriely i sur., 2007 ; Fyall i sur. , 2012 ; Tarlow, 2014 ).

Psychological theory delves into the boundaries of personality to predict under what factors the process of radicalization occurs. Those scholars who embrace psychology to explain the evolution of modern terrorism are paying attention to the role of frustration, poverty or resentment as a key factor in hatred and terrorism. In the same way that modern tourism flourishes only in consolidated democracies or developed cultures interrupted by the benefits of freedom and mobility, it is important to view failed states or undemocratic nations as the fertile foundations of authoritarian and radicalized minds. As a result, hostility to Western tourists conceals a repressed psychological outrage, which is eventually rehabbed by violence. As a Factor of Democracy Sönmez, 1998; Sönmez and Graefe, 1998; Scheyvens and Momsen, 2008; Rashid and Robinson, 2010; Scheyvens, 2012).

One of the most striking characteristics of terrorist groups is their strict adherence to ideology. Ideologies provide a narrative structure with which to interpret new information and past events. Because terrorist groups (without exception) consist of an outraged minority, their ideology is often focused on the victim narrative. The neural infrastructure built around maintaining ideological righteousness is immeasurable. Dozens of different biases have been identified, named, and characterized. Because these processes take place automatically, in areas of our brain that are largely inaccessible to conscious introspection, we are subject to their effects, whether we like it or not. As the great psychologist Lee Ross said, we are "naive realists" who believe that we see the world objectively, while those who disagree with us are inherently irrational. Some groups, not others, are again not owned by this "blind spot" but are the result of the existence of a human brain designed to function effectively. A sign of terrorism is indiscriminate violence against 'out-of-group' members. Our brains are shaped by the ability to care deeply, but also to kill. This deep ambivalence is potentially problematic. A society filled with people who are fundamentally compassionate and very violent could prove unstable. Part of the evolutionary solution to this problem seems to have been related to processes that support prosociality (e.g., empathy) and processes that enable violence (e.g., dehumanization) to differentiate within and outside the group. That way, people would potentially love each other in the group and hate the outside group; to fight and die 
on behalf of us and be ready to kill them. The psychological processes that drive deep altruism (for the group) and motivate extreme violence (towards the outside group) are still living in us.

\section{Instead of Conclusion}

This paper uses an interdisciplinary approach to place the tourism industry within the neuroscience as an area of growing global change and tourism problems and potential directions for a new approach in the digital era.

Emphasis, the whole paper refers indirectly to the Istrian region as potential ideas for a tourism strategy in the face of new technologies, trends involving life-threatening programs and cooperation with Europe / Asia (China) in the field of financial and highly professional medical partnership. All this requires in-depth market analysis and possible predictions of medical tourism in a combination of four points (empathy, neuroscience culture, ethics and epistemology).

Researchers say the brain's reward network could play an influential role in assessing opportunities to acquire new information, such as rewards such as food or financial gain, but also rewards in devising innovative approaches in tourism or any branch. We have a "thirst for knowledge", but sometimes "ignorance is bliss", so how do you choose between these two states of mind at any time?

Thus, the aim of the paper was not to investigate tourists' expectations when visiting a particular place that related to several features of the selected destination: culture, architecture, gastronomy, infrastructure, landscape, events, shopping. Of course, these features attract people to their destination and add to the overall travel experience. On the whole, they are key aspects of a destination and have a strong impact on their success. Therefore, the study of the market segment of urban destinations is especially important because of its impact on the economic development of cities as well as the competitiveness of the destination, which relates to the brand's ability to occupy a niche in the market in the long run. This is the potential of creating and integrating value-added products to sustain resources while maintaining their position in the market over other competitors. For the brand image, the uniqueness of the destination is crucial for the desired positioning, and this makes the brand unique and recognizable to tourists, or a clear need to promote the city's tourism products and packages, its cultural attractions and gastronomy in competitive networks as a European urban destination. In addition, infrastructure and transport, landscape and natural resources, events and sports also have a more stable presence through communication practices, although these categories are less important in discourse than previous ones.

In light of the above, the question is how relevant is neuroscience to tourism in the digital age and knowledge and strategy creation?

The application of neuroscience in tourism aims at understanding the cultural and genetic diversity that shapes the human mind, brain and behavior across multiple time scales, mirror neurons, a neuroethics that could respond to the preferences of a tourist destination.

The role and impact of neuroscience in tourism can be linked to the decisions of individuals based on the integration of different disciplines including medicine, psychology, sociology and tourism. Research into the neural mechanisms of tourists' behavior is the backbone in tourism research. Neuroscience tools measure some components in the human body such as happiness, satisfaction and reasons for returning to a destination by collecting neurophysiology data, information on cognitive and emotional processes using neuroscientific tools (monitoring and programming) incorporating neurophysiological data into the management information system (Ma and $\mathrm{Hu}$ et al., 2014).

The research covered four points involving neuroscience in tourism: empathy, the culture of the ethics of neuroscience, and epistemology. This justifies a goal that outlines an interdisciplinary network of understanding tourism through key mirror principles of neurons that can contribute to explaining some important aspects of tourism in a neurological context, where many modalities are interconnected; guest-host) in a culture of neuroscience and neuroethics.

Cultural neuroscientists study cultural variation in mental, neural, and genomic processes as a means of articulating a two-way relationship between these processes and their emergent properties using a variety of methods. Cultural neuroscience researchers are motivated by two fundamentally intriguing yet unanswered questions about the origin of human nature and human diversity: how cultural traits (e.g., values, beliefs, practices) shape neurobiology (e.g., genetic and neural processes) and behaviors, and how neurobiological mechanisms (eg genetic and neural processes) facilitate the emergence and transfer of cultural traits? (Journal, Social Cognitive and Affective Neuroscience, 2010).

Research has made significant gains in understanding the neural basis of empathy. Convergent strands of evidence support simulation-based empathy models (empathy for pain employees involved in first-hand pain experience) Similarly, empathy for other different sensory and affective states (tactile pleasure, fear) affects the networks involved in first-hand experience of these conditions. Such empathetic simulations are not unique to humans, but can be observed on social species. Both emotional empathy and mentalizing (cognitive empathy) can promote concern or compassion, an outcome variable of particular interest to researchers and practitioners. 
Empathy - the ability to share the feelings of others - is fundamental to our emotional and social lives. Previous human imaging studies focused on empathy for someone else's pain have consistently shown activation in regions that are also involved in the experience of direct pain, especially the anterior insula and anterior and middle cerebral cortex. Evidence suggests that empathy is based in part on shared first-hand representations and indecent experiences of affective states. Empathy often involves coactivation in further networks related to social cognition, depending on the specific situation and information available in the environment. Empathy-related insular and cingulate activity may reflect domain-general computations representing and predicting feeling states in self and others, likely guiding adaptive homeostatic responses and goal-directed behavior in dynamic social contexts.

Neuroscience blends with technology in ways that will have a huge impact on society. This will not be limited to improving health and brain function. There will also be deep ethical challenges and perhaps even redefining what it means to be human.

The concept of cosmopolitanism plays an important role in our multicultural world because it helps to understand and find solutions to problems that may be caused by the globalized situational world. Tourism helps to see other countries and peoples with their own eyes. At the same time, it brings new challenges in understanding foreign cultures, which can either lead to positive or negative results in the development of certain cosmopolitan characteristics.

The difficulty in understanding the epistemology of empathy lies in changing paradigms that have resulted in empathy being viewed as vague and elusive. Empathy is at the core of all social and intellectual transformations. Humanity is biologically programmed to use empathy for survival, health and well-being. Understanding empathy releases the human capacity for wisdom. The study of the epistemology of empathy is operationally and scientifically relevant in the synthesis of empathy practice theory.

\section{References}

Ahn, Y. J., \& Janke, M. C. Motivations and benefits of the travel experiences of older adults. Educational Gerontology, 37(8), 653-673. https://doi.org/10.1080/03601271003716010

Alistair, W. (2006). Tourism and hospitality marketing: fantasy, feeling and fun. International Journal of Contemporary Hospitality Management, 18(6), 482-495. https://doi.org/10.1108/09596110610681520

Altheide, D. (2006), Terrorist and the Politics of Fear, Altamira Press, Oxford. https://doi.org/10.1177/1532708605285733

Baik, J. H. (2006). Dopamine signaling in reward-related behaviors. Front Neural Circuits, 152.

Beck, D. M. (2013). The appeal of the brain in the popular press. Perspect. Psychol. Sci., 5, 762-766. https://doi.org/10.1177/1745691610388779

Bloch, P. H., Sherrell, D. L., \& Ridgway, N. M. (1986). Consumer search: an extended framework. Journal of Consumer Research, 13(1), 119-126. https://doi.org/10.1086/209052

Bradley, S. D., Angelini, J. R., \& Lee, S. (2007). Psychophysiological and memory effects of negative political ads: Aversive, arousing, and well remembered. Journal of Advertising, 36(4), 115-127. https://doi.org/10.2753/JOA0091-3367360409

Bromberg-Martin, E. S., Matsumoto, M., Hikosaka, O. (2010). Dopamine inmotivational control: rewarding, aversive, and alerting. Neuron., 68(5), 815-834. https://doi.org/10.1016/j.neuron.2010.11.022

Bruni, S., Gerbella, M., Bonini, L., Borra, E., Coudé, G., Ferrari, P. F., ... Rozzi, S. (2017). Cortical and subcortical connections of parietal and premotor nodes of the monkey hand mirror neuron network. Brain Structure and Function. https://doi.org/10.1007/s00429-017-1582-0

Cerri, G., Cabinio, M., Blasi, V., Borroni, P., Iadanza, A., Fava, E., ... Bello, L. (2014). Zrcalni neuronski sustav i neobičan slučaj područja Brocas. Kartiranje ljudskog mozga, 36(3), 1010-1027. https://doi.org/10.1002/hbm.22682

Chamberlain, L., \& Broderick, J. A. (2007). The application of physiological observation methods to emotion research. Qualitative Market Research: An International Journal, 10(2), 199-216. https://doi.org/10.1108/13522750710740853

Coen, E. (2012). Cells to Civilization (1st ed.). Princeton, NJ: Princeton University Press. https://doi.org/10.1515/9781400841653

Cook, R. (2012). The ontogenetic origins of mirror neurons: evidence from 'tool-use' and 'audiovisual' mirror neurons. Biology Letters, 8(5), 856-885. https://doi.org/10.1098/rsbl.2012.0192

Crooks, V., Kingsbury, P., Snyder, J., Johnston, R. (2010). What is known about the patient's experience of medical 
tourism? A scoping review. Biomed Central. https://doi.org/10.1186/1472-6963-10-266

Dawson, M. E., Schell, A. M., \& Filion, D. L. (2007). The Electrodermal System. Handbook of psychophysiology, 159. https://doi.org/10.1017/CBO9780511546396.007

Dehdashti, S. Z., \& Nakhaei, K. H. (2016). An entropy (Shannon) based approach for determining importance weights of influencing factors in selecting medical tourism destinations. Int J Travel Med Glob Health, 4(4), 115-121. https://doi.org/10.21859/ijtmgh-040406

Dekker, S., Lee, N. C., Howard-Jones, P., \& Jolles, J. (2012). Neuromyths in education. Prevalence and predictors of misconceptions among teachers. Front. Psychol. 3, 429. https://doi.org/10.3389/fpsyg.2012.00429

Diken, B. \& Laustsen, C.B. (2002). Zones of indistinction: security, terror. And Bare Life. Space and Culture, 5(3), 290-307. https://doi.org/10.1177/1206331202005003009

Doyle, T., \& Zakrajsek, T. (2013). The New Science of Learning: How to Learn in Harmony with Your Brain. Sterling, VA: Stylus Pub.

Enders, W., \& Sandler, T. (2011). The Political Economy of Terrorism, Cambridge University Press. Cambridge, MA. https://doi.org/10.1017/CBO9780511791451

Floyd, M. F. (1997). Pleasure, arousal, and dominance: Exploring affective determinants of recreation satisfaction. Leisure Sciences, 19(2), 83-96. https://doi.org/10.1080/01490409709512241

Fredrikson, M., \& Öhman, A. (1979). Cardiovascular and Electrodermal Responses Conditioned to Fear- Relevant Stimuli. Psychophysiology, 16(1), 1-7. https://doi.org/10.1111/j.1469-8986.1979.tb01428.x

Gallese, V. (2003). The 'Shared Manifold' Hypothesis From Mirror Neurons To Empathy. Journal of Conscienceness Studies, 36(4), 171-180. https://doi.org/10.1159/000072786

Gretzel, U., Fesenmaier, D. R., Formica, S., \& O’Leary, J. T. (2006). Searching for the future: Challenges faced by destination marketing organizations. Journal of Travel Research, 45(2), 116-126. https://doi.org/10.1177/0047287506291598

Guy, J. S. (2016). Beyond global modernity, global consciousness and global governmentality: The symmetrical anthropology of globalization. European Journal of Social Theory, 19, 451-467. https://doi.org/10.1177/1368431016655066

Harvey, D. (1990). The condition of postmodernity. Malden, MA: Blackwell.

Heyes, C. (2010). Where do mirror neurons come from? Neuroscience \& Biobehavioral Reviews, 34(4), 575-583. https://doi.org/10.1016/j.neubiorev.2009.11.007

Holbrook, M. B. (2006). Consumption experience, customer value, and subjective personal introspection: An illustrative photographic essay. Journal of Business Research, 59(6), 714-725. https://doi.org/10.1016/j.jbusres.2006.01.008

Hosany, S. (2012). Appraisal Determinants of Tourist Emotional Responses. Journal of Travel Research, 51(3), 303-314. https://doi.org/10.1177/0047287511410320

Hosany, S., \& Gilbert, D. (2010). Measuring Tourists' Emotional Experiences toward Hedonic Holiday Destinations. Journal of Travel Research, 49(4), 513-526. https://doi.org/10.1177/0047287509349267

Hosany, S., \& Prayag, G. (2013). Patterns of tourists' emotional responses, satisfaction, and intention to recommend. Journal of Business Research, 66(6), 730-737. https://doi.org/10.1016/j.jbusres.2011.09.011

Howie, L. (2012). Witnesses to Terror: Understanding the Meanings and Consequences of Terrorism, Plagrave-Macmillan, Basingstoke. https://doi.org/10.1057/9781137271761_2

Iacoboni, M. (2009). Mirroring People: The Science of Empathy and How We Connect with Others (1st ed.). New York, NY: Picador.

Ito, T. A., Larsen, J. T., Kyle, N., \& Cacioppo, J. T. (1998). Negative information weighs more heavily on the brain: The negativity bias in evaluative categorizations. Journal of Personality and Social Psychology, 75(4), 887-900. https://doi.org/10.1037/0022-3514.75.4.887

Jerison, H. J. (1973). Introduction to Progressive Evolution of the Brain. Evolution of the Brain and Intelligence, 283-285. https://doi.org/10.1016/B978-0-12-385250-2.50022-5

Johnson, A. R., \& Stewart, D. W. (2005). A reappraisal of the role of emotion in consumer behavior: Traditional and contemporary approaches. In N. K. Malhotra (Eds.), Review of Marketing Research, NY: M.E. Sharpe, 3-33. https://doi.org/10.1108/S1548-6435(2004)0000001005 
Keysers, C., Kohler, E., Umilt, M. A., Nanetti, L., Fogassi, L., \& Gallese, V. (2003). Audiovisual mirror neurons and action recognition. Experimental brain research, 153(4), 628-636. https://doi.org/10.1007/s00221-003-1603-5

Khan, Mohammad Jamal, Shankar Chelliah, and Mahmod Sabri Haron. (2016). Medical tourism destination image formation process: A conceptual model. International Journal of Healthcare Management, 9(2), 134-143. https://doi.org/10.1080/20479700.2016.1142046

Kilner, J. M., \& Blakemore, S. (2007). How does the mirror neuron system change during development? Developmental Science, 10(5), 524-526. https://doi.org/10.1111/j.1467-7687.2007.00632.x

Knafo, A., Zahn-Waxler, C., Davidov, M., Hulle, C. V., Robinson, J. L., \& Rhee, S. H. (2009). Empathy in early childhood: Genetic, environmental, and affective contributions. In O. Vilarroya, S. Altran, A. Navarro, K. Ochsner, \& A. Tobeña (Eds.), Values, empathy, and fairness across social barriers. (Vol. 1167, pp. 103-114). New York, NY: New York Academy of Scienceshttps://doi.org/10.1111/j.1749-6632.2009.04540.x

Korstanje, M. E. (2015). The spirit of terrorism: tourism, unionization and terrorism. Pasos Revista de Turismo y Patrimonio Cultural, 13(1), 239. https://doi.org/10.25145/j.pasos.2015.13.016

Korstanje, M. E. (2017). Terrorism, Tourism and the End of Hospitality in the West, Springer Nature. New York, NY. https://doi.org/10.1007/978-3-319-52252-4

Krugman, D. M., Fox, R. J., Fletcher, J. E., Fischer, P. M., \& Rojas, T. H. (1994). Do adolescents attend to warnings in cigarette advertising? An eye-tracking approach. Journal of Advertising Research, 34(6), 39-39.

Lamm, C., Decety, J., \& Singer, T. (2011). Meta-analytic evidence for common and distinct neural networks associated with directly experienced pain and empathy for pain. NeuroImage, 54(3), 2492-2502. https://doi.org/10.1016/j.neuroimage.2010.10.014

Lane, R. D., Reiman, E. M., Ahern, G. L., Schwartz, G. E., \& Davidson, R. J. (1997). Neuroanatomical correlates of happiness, sadness, and disgust. American Journal of Psychiatry, 154, 926-933. https://doi.org/10.1176/ajp.154.7.926

Lane, R. D., Reiman, E. M., Bradley, M. M., Lang, P. J., Ahern, G. L., Davidson, R. J., \& Schwartz, G. E. (1997). Neuroanatomical correlates of pleasant and unpleasant emotion. Neuropsychologia, 35, 1437-1444. https://doi.org/10.1016/S0028-3932(97)00070-5

LeDoux, J. E. (2000). Emotional circuits in the brain. Annual Review of Neuroscience, 23, 155-184. https://doi.org/10.1146/annurev.neuro.23.1.155

Lee, J. (Jiyeon). (2014). Visitors' emotional responses to the festival environment. Journal of Travel \& Tourism Marketing, 31(1), 114-131. https://doi.org/10.1080/10548408.2014.861726

Lindell, A. K., \& Kidd, E. (2013). Consumers favor "right brain" training: the dangerous lure of neuromarketing. Mind Brain Educ. 7, 35-39. https://doi.org/10.1111/mbe.12005

Ma, Q. G., Hu, L. F., Pei, G. X., Ren, P. Y., \& Ge, P. (2014). Applying Neuroscience to Tourism Management: A Primary Exploration of Neurotourism, Applied Mechanics and Materials, 670-671, 1637-1640. https://doi.org/10.4028/www.scientific.net/AMM.670-671.1637

Marschark, M., Spencer, L. J., Durkin, A., Borgna, G., Convertino, C., Machmer, E., ... Trani, A. (2015). Understanding Language, Hearing Status, and Visual-Spatial Skills. Journal of Deaf Studies and Deaf Education, 20(4), 310-330. https://doi.org/10.1093/deafed/env025

Mauss, I. B., \& Robinson, M. D. (2009). Measures of emotion: A review. Cognition \& Emotion, 23(2), 209-237. https://doi.org/10.1080/02699930802204677

Mauss, I. B., Levenson, R. W., McCarter, L., Wilhelm, F. H., \& Gross, J. J. (2005). The Tie That Binds? Coherence Among Emotion Experience, Behavior, and Physiology. Emotion, 5(2), 175-190. https://doi.org/10.1037/1528-3542.5.2.175

McCabe, D. P., \& Castel, A. D. (2008). Seeing is believing: the effect of brain images on judgement of scientific reasoning. Cognition, 107, 343-352. https://doi.org/10.1016/j.cognition.2007.07.017

Monroe, K. (1986). The Influence of Price Differences and Brand Familarity of Brand Preferences.

Morrison, I. (2002). Mirror neurons and cultural transmission. Mirror Neurons and the Evolution of Brain and Language Advances in Consciousness Research, 333-340. https://doi.org/10.1075/aicr.42.25mor

Mukamel, R., Esktrom, A. D., Kaplan, J., Iacoboni, M., \& Fried, I. (2011). Single neuron responses in humans during execution and observation of actions. Current Biology, 20(8), 750-756. https://doi.org/10.1016/j.cub.2010.02.045 
Neuhauser, H., Leopold, M., von Brevern, M., Arnold, G., \& Lempert, T. (2001). The interrelations of migraine, vertigo, and migrainous vertigo. Neurology, 56(4), 436-441. https://doi.org/10.1212/WNL.56.4.436

Nicholson, N. (1998). How Hardwired Is Human Behavior? Harvard Business Review, 76(4), 134-147.

Pasquinelli, E. (2012). Neuromyths: why do they exist and persist? Mind Brain Educ. 6, 89-96. https://doi.org/10.1111/j.1751-228X.2012.01141.x

Paulhus, D. L. (2002). Socially desirable responding: The evolution of a construct The role of constructs in psychological and educational measurement (pp. 49-69): L. Erlbaum Associates.

Phan, L. K., Wager, T., Taylor, S. F., \& Liberzon, I. (2002). Functional Neuroanatomy of Emotion: A meta-analysis of emotion activation studies in PET and fMRI. NeuroImage, 16, 331-348. https://doi.org/10.1006/nimg.2002.1087

Pieters, R., \& Wedel, M. (2004). Attention capture and transfer in advertising: Brand, pictorial, and text-size effects. Journal of Marketing, 68(2), 36-50. https://doi.org/10.1509/jmkg.68.2.36.27794

Pieters, R., Rosbergen, E., \& Wedel, M. (1999). Visual Attention to Repeated Print Advertising: A Test of Scanpath Theory. Journal of Marketing Research, 36(4), 424-438. https://doi.org/10.1177/002224379903600403

Pizam, A., \& Smith, G. (2000). Turizam i terorizam: kvantitativna analiza glavnih terorističkih akata i njihov utjecaj na turistička odredišta, Turistička ekonomija, 6(2), 123-138.

Poels, K., \& Dewitte, S. (2006). How to capture the heart? Reviewing 20 years of emotion measurement in advertising. Journal of Advertising Research, 46(1), 18-37. https://doi.org/10.2501/S0021849906060041

Prebensen, N. K., Woo, E., Chen, J. S., \& Uysal, M. Experience quality in the different phases ofa tourist vacation: A case of northern Norway. Tourism Analysis, 17(5), 617-627.

Rashid, T., \& Robinson, N. (2010). Crisis and risks in tourism: death takes a holiday-debunking the myth of terrorism and its psychological impact on the tourism industry", International Journal of Tourism Policy, 3(4), 348-353. https://doi.org/10.1504/IJTP.2010.040393

Reiman, E. M., Lane, R. D., Ahern, G. L., Schwartz, G. E., Davidson, R. J., Friston, K. J., ... Chen, K. (1997). Neuroanatomical correlates of externally and internally generated human emotion. American Journal of Psychiatry, 154, 918-925. https://doi.org/10.1176/ajp.154.7.918

Rigoni, D., Demanet, J., \& Sartori, G. (2015). Happiness in action: The impact of positive affect on the time of the conscious intention to act. FrontPsychol., 1307. https://doi.org/10.3389/fpsyg.2015.01307

Rogalsky, C., Love, T., Driscoll, D., Anderson, S. W., \& Hickok, G. (2011). Are mirror neurons the basis of speech perception? Evidence from five cases with damage to the purported human mirror system. Neurocase, 17(2), 178-187. https://doi.org/10.1080/13554794.2010.509318

Rutledge, R. B., Skandali, N., Dayan, P., \& Dolan, R. J. Dopaminergicmodulation of decision making and subjective well-being. J. Neurosci., 35(27), 9811-9822. https://doi.org/10.1523/JNEUROSCI.0702-15.2015

Ryan, C. (1993). Crime, violence, terrorism and tourism: an accidental or intrinsic relationship? Tourism Management, 14(3), 173-183. https://doi.org/10.1016/0261-5177(93)90018-G

Ryan, C. (2002). Equity, management, power sharing and sustainability - issues of the 'new tourism'. Tourism Management, 23(1), 17-26. https://doi.org/10.1016/S0261-5177(01)00064-4

Shahvali, M., Beesley, L., Rahimi, R., \& Shahvali, R. (2016). Measuring empathy within hotel employees. Anatolia: An International Journal of Tourism \& Hospitality Research, 27(2), 237-250. https://doi.org/10.1080/13032917.2015.1114956

Sheller, M., \& Urry, J. (2006). The new mobilities paradigm. Environment and Planning A, 38(2), 207-226. https://doi.org/10.1068/a37268

Sigmund, K. (2017). Games of life: Research in Ecology, Evolution and Behavior( 3rd. Ed.). Mineola, NY: Dover Publications, Inc.

\section{Copyrights}

Copyright for this article is retained by the author(s), with first publication rights granted to the journal.

This is an open-access article distributed under the terms and conditions of the Creative Commons Attribution license which permits unrestricted use, distribution, and reproduction in any medium, provided the original work is properly cited. 